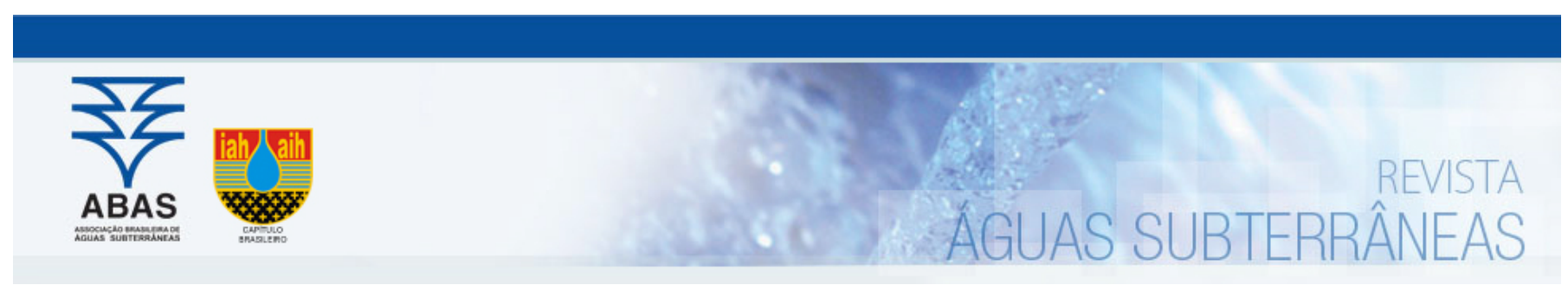

Estudos de Caso e Notas Técnicas

\title{
Avaliação da qualidade de águas subterrâneas localizadas no litoral, serra e sertão do Estado do Ceará destinadas ao consumo humano
}

\section{Evaluation of the quality of groundwaters located in the coast, high altitude and hinterland of the State of Ceará for human consumption}

\begin{abstract}
Erika Sampaio Braga ${ }^{1}$;Caio Barroso Freitas Barroso Freitas; Luzia Suerlange Araújo dos Santos Mendes; Marisete Dantas de Aquino ${ }^{1}$
\end{abstract}
1 Universidade Federal do Ceará (UFC), Fortaleza, CE, Brasil.

$\bowtie$ andreierika@yahoo.com.br, al_caiobf@hotmail.com, suerlange@bol.com.br, marisete@ufc.br

Resumo

Palavras-chave:

Águas subterrâneas.

Parâmetros químicos.

Qualidade da água.

Potabilidade.

\begin{abstract}
O estado do Ceará, localizado na região nordeste do Brasil, encontra-se na sua totalidade incluído no chamado polígono das secas, com um regime pluviométrico caracterizado por uma irregularidade de chuvas, no tempo e no espaço, que representa a principal condicionante desfavorável ao aproveitamento de seus recursos naturais. Em virtude do regime pluviométrico sazonal, torna-se necessário a captação de águas subterrâneas, captadas de poços, para abastecimento da população. A maioria desses poços estão inseridos no contexto geológico de rochas do embasamento cristalino, em que fatores antrópicos como fossas sépticas podem comprometer a qualidade da água. Tais fatores contribuem para que a água captada não tenha uma qualidade adequada para o consumo humano. Com base nesse contexto, essa pesquisa teve como principal objetivo avaliar a qualidade dessas águas. Foram coletadas amostras de águas subterrâneas de poços localizados em três tipos de relevo diferentes: litoral, serra e sertão. Foram realizadas análises químicas dos parâmetros $\mathrm{pH}$, dureza total, cloretos e nitratos e comparadas com a legislação vigente, a Portaria $n^{\circ} 2914$ de 12 de dezembro de 2011 do Ministério da Saúde. Verificou-se que a maioria das águas era inadequada para o consumo humano.
\end{abstract}

Abstract

Keywords:

Groundwater.

Chemical parameters.

Water quality.

Potability.

The state of Ceará, located in the northeastern region of Brazil, is in its totality included in the so-called drought polygon, with a pluviometric regime characterized by an irregularity of rains, in time and space, which represents the main condition that is unfavorable to exploitation of its natural resources. Due to the seasonal rainfall regime, it becomes necessary the capitation of groundwater, from wells, to supply the population. Most of these wells are embedded in the geological context of crystalline basement rocks, where anthropogenic factors such as septic tanks may compromise water quality. Such factors contribute so that the abstracted water does not have a suitable quality for human consumption. Based on this context, this research had as main objective to evaluate the quality of these waters. Groundwater samples were collected from wells located in three different types of relief: coast, high altitude, and hinterland. Chemical analyzes of the parameters $\mathrm{pH}$, total hardness, chlorides, and nitrates were performed and compared to the current legislation, the Ordinance No. 2914 of December 12, 2011 of the Ministry of Health. It was verified that most of the waters were inadequate for human consumption.

\section{INTRODUÇÃO}

0 trabalho tem como objetivo realizar pesquisas na avaliação da qualidade dos recursos hídricos subterrâneos em diferentes formações: litoral, serra e sertão, do estado do Ceará. A aplicação desses estudos se apresenta como ferramenta fundamental de apoio à gestão da água, principalmente em regiões onde o recurso é escasso e limitado. A escassez de água em muitos países com elevada concentração populacional tornou-se fator impeditivo ao desenvolvimento e, em alguns casos, comprometendo a própria subsistência. A região nordeste do Brasil, em especial o estado do Ceará, enfrenta a realidade de um regime pluviométrico marcado por extrema irregularidade de chuvas no tempo e no espaço. Nesse cenário, a água constitui um bem natural de elevada limitação ao desenvolvimento socioeconômico desta região e, até mesmo, na subsistência da população, notadamente no seu núcleo central caracterizado pelo semiárido. A ocorrência cíclica dessa realidade e seus efeitos catastróficos no âmbito regional são históricos. O enfrentamento dessa problemática passa por soluções com embasamento técnico seguro que direcione os investimentos e o melhor aproveitamento dos recursos. A potencialização do uso de recursos hídricos subterrâneos, 
frente ao uso ainda insipiente do volume de reservas, vem a ser uma importante solução para o enfrentamento da seca, pois é de conhecimento geral que uma grande quantidade de captações de água subterrânea no semiárido, principalmente em rochas cristalinas, encontra-se desativada e/ou abandonada a partir de problemas diversos, das quais uma parcela poderia voltar a funcionar, e aumentar a oferta de água, a partir de pequenas ações corretivas (CPRM, 1998). A utilização desse recurso hídrico em maior escala pressupõe a realização de estudos amostrais visando avaliar a qualidade da água em diferentes regiões com características distintas de alguns fatores como solo e clima. 0 objetivo é conhecer os fatores ambientais, tanto os naturais como aqueles que são frutos da ação do homem que, direta ou indiretamente, afetam a qualidade da água e, com isso, embasar o direcionamento dos investimentos necessários, seja para elevar os níveis de potabilidade da água, seja para direcionar os investimentos para as regiões onde a água é mais potável. Diante dessa realidade, a esta pesquisa tem como objetivo básico a avaliação da qualidade da água subterrânea em cidades localizadas em três regiões de diferentes características geográficas, a saber: o litoral, a predominância de serra e o sertão.

Especificamente, serão empregadas análises químicas em todas as amostras de municípios dessas três regiões, e os resultados serão comparados com o padrão de potabilidade estabelecido pela legislação do Ministério da Saúde. Estão descritos os principais estudos das fontes de águas subterrâneas, sua origem, localização, composição e impurezas comuns existentes na água. Ademais, foram relatadas as condições físicas e climáticas que interferem na qualidade da água. Segundo Iritani e Ezaki (2009), a água subterrânea é toda água que se encontra sob a superfície da Terra, circulando nos espaços vazios, denominados poros, existentes entre os grãos que formam os solos. Entretanto, do ponto de vista da hidrogeologia, a denominação água subterrânea é atribuída apenas à água do subsolo que circula na zona saturada (FEITOSA et al., 2008).

O limite entre zona saturada e não saturada é comumente conhecido como lençol freático ou nível freático, pois quando perfurado um poço raso, o nível da água observado representa a profundidade do lençol freático naquele ponto (IRITANI; EZAKI, 2009). Se a água subterrânea está contida em solo composto por rochas porosas, como arenito, ou em rochas altamente fraturadas, como pedregulho ou areia, e se as águas mais profundas estão em contato com uma camada de argila ou rochas impermeáveis, então se constitui um reservatório permanente, uma espécie de lago subterrâneo, chamado aquífero (BAIRD, 2002). Capucci et al. (2001) aborda os aquíferos como sendo reservatórios de água subterrânea capazes de não somente armazenar, mas também transmitir água em quantidades que possam ser aproveitadas como fonte de abastecimento para diferentes usos. Os aquíferos sedimentares constituem os mais importantes aquíferos, pelo grande volume de água que armazenam devido a grande profundidade que os poços podem atingir nos sedimentos, e por sua ocorrência em grandes áreas. Esses aquíferos ocorrem nas bacias sedimentares e em todas as várzeas onde se acumularam sedimentos arenosos (ABAS, 2016).

Os aquíferos fissurais são aqueles nos quais a água circula pelas fendas e fissuras resultantes do fraturamento das rochas relativamente impermeáveis (ígneas ou metamórficas) (MMA, 2007).

\section{QUALIDADE DAS ÁGUAS SUBTERRÂNEAS}

O termo "qualidade das águas" refere-se à concentração dos constituintes particulados e dissolvidos na água e que podem ter uma influência direta ou indireta nos seus usos (BECKER, 2010). Ainda conforme Becker (2010), a qualidade de uma água é o que assegura um determinado uso ou conjunto de usos dessa água e é representada por características intrínsecas de natureza física, química, radioativa e biológica, geralmente mensuráveis. Critérios ou padrões são estabelecidos para que as características inerentes daquela água sejam mantidas dentro de certos limites. No Brasil, a legislação vigente que trata de potabilidade da água para consumo humano é a Portaria n 2914 de 12 de dezembro de 2011 do Ministério da Saúde. Um dos principais motivos para se estabelecer esses padrões é a contaminação das águas subterrâneas, que podem ocorrer por inúmeros fatores: as fontes potenciais de poluição provenientes de atividades humanas e a exploração intensiva ou descontrolada de água. A falta de proteção dos poços também gera um risco potencial de poluição, isto é, eles precisam estar devidamente vedados com o fim de se evitar o acesso de contaminantes no aquífero. Segundo Costa et al. (2012), a água subterrânea tem potencial capacidade de transmissão de doenças causadas por microrganismos patogênicos provenientes de fezes de humanos e animais, ou por meio de substâncias químicas em concentração fora dos padrões permitidos pela Portaria 2914/11 MS, por isso torna-se indispensável a verificação e o acompanhamento de sua potabilidade.

\subsection{Caracterização das impurezas presentes na água}

As propriedades físicas, químicas e biológicas da água são usadas como parâmetros para saber se o corpo hídrico está no nível aceitável para o consumo humano. As águas subterrâneas dificilmente são portadoras de características perceptíveis, exceto o sabor, cor, odor, decorrente de sais dissolvidos em quantidade excessiva. As características químicas das águas subterrâneas refletem os meios percorridos, guardando uma relação com os tipos de rochas drenadas e com os produtos das atividades humanas adquiridas ao longo de seu trajeto (ZIMBRES, 2006). Delimitou-se para a consecução dos objetivos deste trabalho a aplicação de quatro parâmetros de análise química, considerados essenciais para a avaliação da qualidade das amostras de água de poços coletadas: potencial hidrogeniônico $(\mathrm{pH})$, dureza total (DT), cloretos $\left(\mathrm{Cl}^{-}\right)$e nitratos ( $\mathrm{NO}_{3}{ }^{-}$.

\section{Potencial hidrogeniônico $(\mathrm{pH})$}

$\mathrm{O} \mathrm{pH}$ representa a concentração de íons hidrogênio, $\mathrm{H}^{+}$, dando uma indicação das condições de acidez, neutralidade e basicidade da água. Trata-se de um parâmetro de caráter operacional importante e deve ser acompanhado para otimizar os processos de tratamento (BAIRD, 2004).

Segundo a ANA (2016), o pH das águas subterrâneas varia geralmente entre 5,5 e 8,5. A Portaria ${ }^{\circ}{ }^{2}$ 2914/11, legislação vigente da qualidade da água para consumo humano, estabelece limites de $\mathrm{pH}$ de 6,0 a 9,5.

Dureza total (DT)

A dureza total é causada principalmente pela presença dos íons cálcio e magnésio, sendo determinada pela soma da dureza de carbonato e dureza de não carbonato, expressa em $\mathrm{mg} \mathrm{CaCO} \mathrm{C}_{3}$ 1. Do ponto de vista sanitário, a dureza não possui significado 
sanitário, mas em elevadas concentrações confere um gosto amargo à água (SPERLING, 2005). Elevadas concentrações são indicação da passagem pelo solo, pois esse parâmetro é muitas vezes um reflexo do intemperismo das rochas e dos solos, pela dissolução lenta do calcário e de outros minerais. A Portaria $n^{\circ}$ 2914/11 estabelece limites altos de dureza de até 500 mg.L-1. Segundo Sperling (2005), águas de elevada dureza possuem efeitos laxativos e sabor desagradável.

\section{Cloretos (Cl-)}

A presença elevada do íon cloreto $(\mathrm{Cl}-)$ pode ser um reflexo da dissolução de minerais, intrusão de água do mar ou pela mistura, recente ou remota, com águas residuárias de origem doméstica, industrial e/ou de irrigação (BRAGA et al., 2005). Concentrações altas de cloretos podem restringir o uso da água em razão do sabor que eles conferem e pelo efeito laxativo que eles podem provocar (VALENTE, 2006). No padrão de potabilidade brasileiro, citado anteriormente, o valor máximo permitido é o de $250 \mathrm{mg}$.L1 .

\section{Nitratos $\left(\mathrm{NO}_{3}^{-}\right)$}

Os íons nitratos e nitritos são substâncias químicas derivadas do nitrogênio e são encontrados de forma natural na água e no solo em baixas concentrações. A deposição de matéria orgânica no solo, como acontece quando se utiliza fossas e sumidouros, aumenta drasticamente a quantidade de nitrogênio. Esse nitrogênio é biotransformado e, por fim, se transforma na substância inorgânica denominada nitrato que possui grande mobilidade no solo alcançando o manancial subterrâneo e ali se depositando. Águas com indicação de poluição por nitratos são uma indicação de poluição mais remota, por ser este o produto final de oxidação do nitrogênio. As principais fontes de poluição são decomposição, efluentes de indústrias metalúrgicas, infiltração e oxidação de esgotos, e canalizações defeituosas. Em elevadas concentrações, o nitrato está adjunto à doença da metahemoglobinemia, ou síndrome do bebê azul, que dificulta o transporte de oxigênio na corrente sanguínea de bebês podendo acarretar a asfixia. Em adultos, a atividade metabólica interna impede a conversão do nitrato em nitrito, que é o agente responsável por essa enfermidade. $\mathrm{O}$ valor máximo é de $10 \mathrm{mg} \mathrm{N}-\mathrm{NO}_{3}$. $^{-1}{ }^{-1}$ em água potável como está descrito na Portaria $n^{\circ}$ 2.914/11.

\subsection{Estudo das condições físico-climáticas dos municípios estu- dados do Ceará}

De acordo com Bezerra (2004) e a Companhia de Gestão de Recursos Hídricos do Ceará (COGERH, 2000), o clima do Ceará é predominantemente semiárido e o território estadual está sujeito a adversidades climáticas caracterizadas por irregularidades na distribuição interanual de precipitação. No que se refere à temperatura, o Estado do Ceará, por estar em latitudes próximas à linha do Equador, apresenta-se com temperaturas médias anuais elevadas: uma média de $26^{\circ} \mathrm{C}$ no litoral podendo alcançar o patamar de $28^{\circ} \mathrm{C}$ para as zonas interiores de sertão e entre $22 \mathrm{e}$ $26^{\circ} \mathrm{C}$ nas regiões serranas, entre 500 e $900 \mathrm{~m}$, podendo atingir valores inferiores a $22^{\circ} \mathrm{C}$ (FUNCEME, 2015). Por sua vez, as médias das temperaturas máximas, em torno de $33^{\circ} \mathrm{C}$ a $34^{\circ} \mathrm{C}$, e mínimas de $22^{\circ} \mathrm{C}$ a $23^{\circ} \mathrm{C}$, refletem a estabilidade do regime térmico; nas zonas litorâneas a redução se observa mais na temperatura máxima, que se situa com maior frequência entre $31^{\circ} \mathrm{C}$ a $32^{\circ} \mathrm{C}$ (COGERH, 2000). No que diz respeito à formação hidrogeológica do estado do Ceará, constitui-se, basicamente, de duas formações: as coberturas sedimentares e o embasamento cristalino. Como observado na Figura 1, a maior parte do território cearense é enquadrado dentro do embasamento cristalino, aproximadamente $87 \%$, que ocupam, predominantemente, a parte central do território cearense, capeadas por delgados solos ou manchas de sedimentos (ANDRADE et al, 2010).

De um conjunto de 184 municípios que compõem o Estado do Ceará, foram estudados 46 municípios, sendo: 12 característicos da região litorânea; 13 característicos da região serrana; e 21 característicos da região dos sertões.

\section{Região de litoral}

Observa-se na Figura 1 que os municípios em estudo referentes a região litorânea têm como domínio hidrogeológico principal as coberturas sedimentares, que são caracterizados principalmente por sedimentos da Formação Barreiras e depósitos aluvionares. A Formação Barreiras caracteriza-se por uma expressiva variação faciológica, com intercalações de niveis mais e menos permeáveis, o que the confere parâmetros hidrogeológicos variáveis de acordo com o contexto local. Os depósitos aluvionares são representados por sedimentos areno-argilosos recentes, que ocorrem margeando as calhas dos principais rios e riachos que drenam a região, apresentando, em geral, uma boa alternativa como manancial, tendo uma importância relativa alta do ponto de vista hidrogeológico, principalmente em regiões semiáridas com predomínio de rochas cristalinas. Normalmente, a alta permeabilidade dos termos arenosos compensa as pequenas espessuras, produzindo vazões significativas (CPRM, 1998). Segundo CPRM (1998), grande parte das captações de águas subterrâneas existentes nesses municípios é de rochas sedimentares com exceção de alguns municípios que compartilham também, em pequena parte, do domínio das rochas cristalinas. Conforme Feitosa et al. (2008), o clima exerce sua principal influência no problema da qualidade da água. Em regiões de elevada pluviosidade, os sais solúveis são lixiviados resultando em baixos teores de salinidade das águas subterrâneas. É o que ocorre nas regiões litorâneas do nordeste, com precipitações pluviométricas acima de 2.000 $\mathrm{mm} / \mathrm{ano}$.

\section{Região de serra}

Os municípios em estudo referentes à região serrana têm domínio hidrogeológico divido entre as rochas cristalinas, e as coberturas sedimentares que são caracterizadas principalmente por sedimentos da Formação Serra Grande e depósitos aluvionares. Com relação à distribuição dos poços por domínios hidrogeológicos, verificou-se que a maioria dos poços em uso encontra-se em rochas cristalinas (CPRM, 1998). Os sedimentos da Formação Serra Grande são constituídos principalmente por arenitos grossos a conglomeráticos que, normalmente, apresentam um potencial médio sob o ponto de vista da ocorrência de água subterrânea, tanto do ponto de vista quantitativo como qualitativo (CPRM, 1998).

\section{Região de sertão}

Nas regiões dos municípios referentes aos sertões do Ceará, o domínio hidrogeológico das rochas é predominante cristalino (CPRM, 1998). As rochas cristalinas predominam totalmente na 
área e representam o que é denominado comumente de aquífero fissural. Como basicamente não existe uma porosidade primária nesse tipo de rocha, a ocorrência da água subterrânea é condicionada por uma porosidade secundária representada por fraturas e fendas, o que se traduz por reservatórios aleatórios, descontínuos e de pequena extensão. Dentro deste contexto, em geral, as vazões produzidas por poços são pequenas e a água, em fun- ção da falta de circulação e dos efeitos do clima semiárido é, na maior parte das vezes, salinizada. Essas condições atribuem um potencial hidrogeológico baixo para as rochas cristalinas sem, no entanto, diminuir sua importância como alternativa de abastecimento em casos de pequenas comunidades ou como reserva estratégica em períodos prolongados de estiagem (CPRM, 1998).

Figura 1 - Mapa de Localização dos municípios estudados

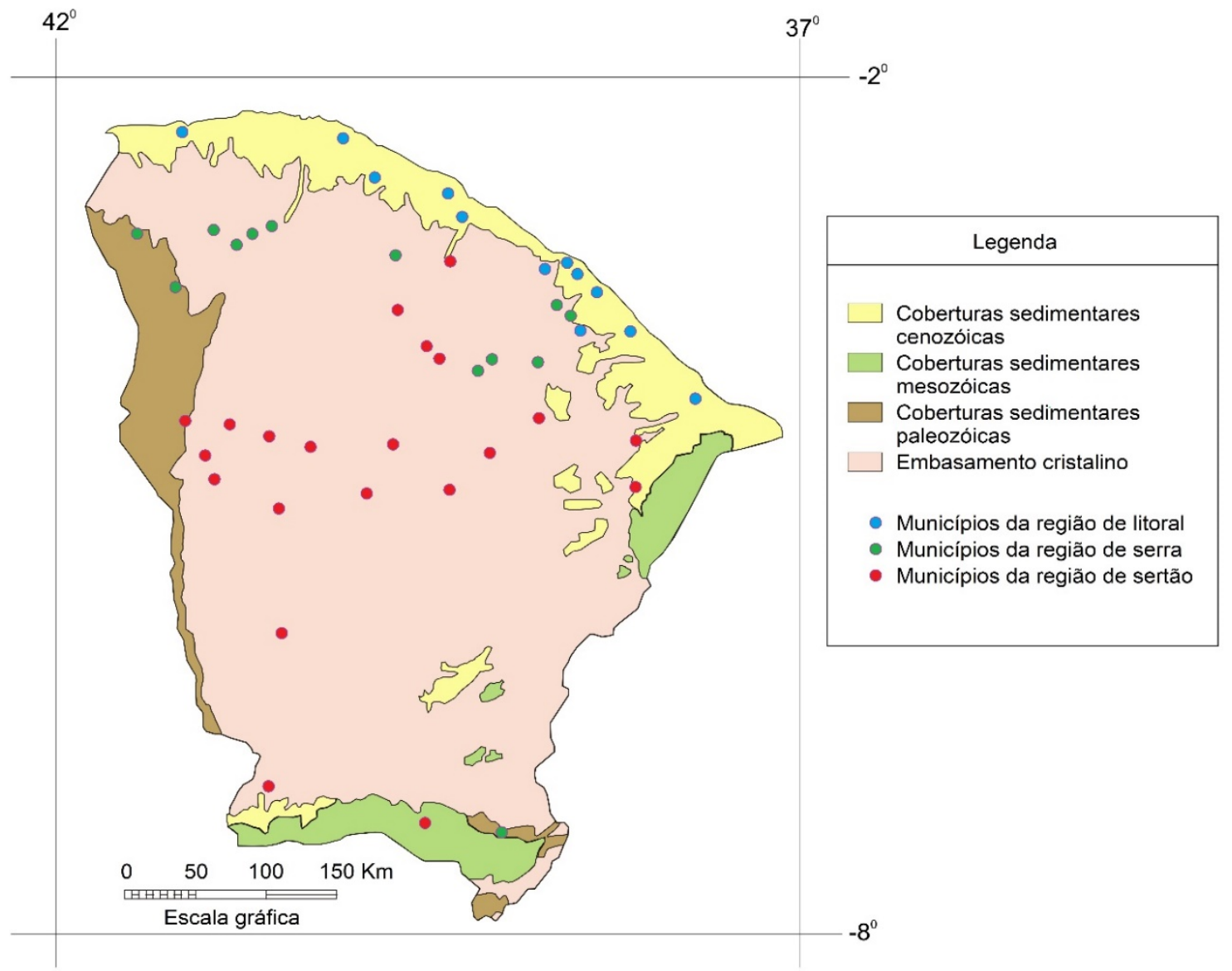

Fonte: Adaptada de Andrade, Meireles e Palácio (2010)

\section{MATERIAIS E MÉTODOS}

Foram coletadas 192 amostras de águas de poços localizados em 46 cidades de diferentes tipos de relevo do interior do Estado do Ceará, sendo: 42 amostras na região litorânea, 54 amostras na região serrana e 96 amostras na região de sertão. Na Tabela 1, estão mostradas as cidades de acordo com o tipo de relevo.

As amostras foram coletadas em frascos adequados e conservadas em caixas de isopor com gelo, de acordo com as normas de coleta recomendado em APHA et al. (2012). Para a avaliação da qualidade das amostras de água de poços coletadas, foram selecionados os parâmetros $\mathrm{pH}$ à $25^{\circ} \mathrm{C}$, dureza total (DT), cloretos $(\mathrm{Cl})$ e Nitratos ( $\mathrm{NO}_{3}{ }^{-}$).

As análises químicas foram realizadas no Laboratório de Química Ambiental (LQA) da Fundação Núcleo de Tecnologia Industrial do Ceará (NUTEC), seguindo-se as metodologias descritas em (APHA et al., 2012), para a determinação dos parâmetros pH à $25^{\circ} \mathrm{C}$, dureza total e cloretos (RODIER, 1990), e para a determinação de nitratos. 
Tabela 1 - Cidades onde as amostras foram coletadas

\begin{tabular}{ccc}
\hline & Amostras/Cidades/Regiões & \multicolumn{1}{c}{ Sertão } \\
\hline Litoral & Serra & Ararendá \\
\hline Amontada & Alcântaras & Boa Viagem \\
Aquiraz & Aracoiaba & Campos Sales \\
Aracati & Aratuba & Canindé \\
Beberibe & Coreaú & Caridade \\
Camocim & Itaitinga & Crateús \\
Caucaia & Itapajé & Crato \\
Eusébio & Massapê & Ibaretama \\
Fortaleza & Meruoca & Independência \\
Horizonte & Milagres & Ipaporanga \\
Itarema & Mulungu & Limoeiro do Norte \\
Paraipaba & Pacatuba & Madalena \\
Trairi & Ubajara & Monsenhor Tabosa \\
& Viçosa do Ceará & Nova Russas \\
& & Quixada \\
& & Quixeramobim \\
& & Russas \\
& & São Luis do Curu \\
& & Tamboril \\
& & Tauá \\
& & Tejuçuoca \\
\hline
\end{tabular}

Fonte: Elaborada pelo autor (2016)

\subsection{Análise estatística das amostras}

Com o fim de se avaliar a qualidade do conjunto das amostras de água para a verificação da conformidade com a legislação vigente, utilizou-se de algumas medidas de ordenação, tendência central e dispersão. Segundo Lapponi (2000), as medidas de ordenamento, tendência central e dispersão compõem a avaliação básica de agrupamentos de dados amostrais. Utilizaram-se as seguintes medidas para a avaliação conjunta das amostras: valor mínimo, percentil, média, mediana, desvio padrão e valor máximo.

\section{RESULTADOS E DISCUSSÃO}

Nas tabelas 2, 3 e 4 a seguir são apresentados os resultados obtidos para as amostras de água subterrâneas coletadas de poços localizados em diferentes cidades de acordo com o tipo de relevo: litoral, serra e sertão.

Tabela 2 - Resultados obtidos para as amostras coletadas na região do litoral

\begin{tabular}{cccc|c}
\hline \multirow{2}{*}{ Litoral } & \multicolumn{4}{c}{ Resultados } \\
\cline { 2 - 5 } & pH à 25 ${ }^{\circ} \mathrm{C}$ & $\begin{array}{c}\text { Dureza total } \\
\left(\mathrm{mgCaCO}_{3}-1\right)\end{array}$ & $\begin{array}{c}\text { Cloretos } \\
\left(\mathrm{mgCl}^{-1} \text { - }\right)\end{array}$ & $\begin{array}{c}\text { Nitratos } \\
\left(\mathrm{mgNNO}_{3}-\mathrm{L}^{-1}\right)\end{array}$ \\
\hline Mínimo & 3,67 & 5,0 & 6,0 & 0,028 \\
Percentil 25\% & 6,04 & 29,9 & 70,7 & 0,076 \\
Mediana & 6,45 & 159,4 & 149,0 & 0,216 \\
Média & 6,41 & 384,6 & 606,5 & 4,865 \\
Percentil 75\% & 6,85 & 536,1 & 839,4 & 2,698 \\
Desvio Padrão Sx & 0,79 & 552,8 & 880,2 & 12,371 \\
Máximo & 8,12 & $2.471,2$ & $3.450,2$ & 59,2 \\
Portaria 2914/11 MS & $6,0-9,5$ & 500,0 & 250,0 & 10,0 \\
\hline
\end{tabular}

Fonte: Elaborada pelo autor (2016)

Como mostrado na Tabela 2, apenas as $25 \%$ menores amostras de litoral apresentam $\mathrm{pH}$ fora da faixa estabelecida pela Portaria 2914/11 MS. Nesse parâmetro, os dados se apresentaram simétricos; isso sempre ocorre quando a média é estatisticamente igual à mediana, isto é, os dados se aproximam a uma Distribuição Normal. Dessa forma, conhecendo-se apenas a média e o desvio padrão desses dados é possível calcular a probabilidade de uma nova amostra da região litorânea e assumir determinado valor (LAPPONI, 2000). No que diz respeito à dureza total, a região litorânea foi a região que apresentou os melhores índices de conformidade, com $75 \%$ das amostras abaixo do valor máximo permitido (VMP). Tal comportamento era esperado, pois o litoral é caracterizado principalmente pelo domínio hidrogeológico das formações sedimentares; essas formações rochosas tendem a formar aquíferos com menores índices salinos em comparação a aquíferos fissurais, ou seja, de embasamento cristalino. Percebese uma dispersão acentuada dos dados em torno da média, caracterizados pelo alto desvio padrão e claro distanciamento entre valores mínimo e máximo. A dispersão, também, está sendo muito influenciada por valores extremos acima da mediana, o que sempre ocorre quando a média é superior à mediana. Com relação ao parâmetro cloretos, aplicando-se a fórmula de percentil, isto é do ordenamento das amostras, obtêm-se que 65\% das amostras coletadas apresentam concentração abaixo do VMP da 
Portaria. Semelhantemente aos resultados de dureza, os dados de cloretos também apresentam elevada dispersão em torno da média. Os resultados para o parâmetro cloretos podem ser justificados pelas atividades humanas, como por exemplo, o lançamento de efluentes, principalmente sanitários nos rios e riachos, contaminando suas águas que percolam o solo atingindo o lençol freático, justificando-se as elevadas concentrações de cloretos, já que os íons cloretos também podem ser provenientes dos efluentes sanitários. De acordo com Becker (2010), nas regiões costeiras, através da chamada intrusão da língua salina, são encontradas águas com níveis altos de cloretos. Os cloretos provocam reações fisiológicas quando ingeridos em grande quantidade.

Dos quatro parâmetros analisados, os íons nitratos apresentaram a maior quantidade de amostras em conformidade com a legislação. Aplicando-se os cálculos de ordenamento, obteve-se que $90 \%$ das amostras se enquadram no permitido pela legislação para o consumo humano. Nota-se que, assim como dureza e cloretos, os dados de nitratos também revelaram elevada dispersão em torno da média, também fortemente influenciada por valores extremos acima da mediana. Os íons nitratos podem estar presentes em águas por ações antrópicas, tanto por decomposição da matéria orgânica por bactérias, como pela infiltração no solo de fertilizantes usados nas plantações. A poluição das águas subterrâneas ocorre quando os agentes contaminantes percolam o solo atingindo assim o lençol freático. A poluição dos recursos hídricos por ações antrópicas pode acarretar inúmeros problemas à saúde humana, pois a água é empregada com veículo pelos agentes patogênicos na disseminação de doenças (GRABOW, 1996 apud GREGHI, 2005). Provavelmente, a presença de íns nitratos deva-se ao uso de fertilizantes na agricultura e a proximidade de fossas sépticas ao poço. Águas utilizadas para abastecimento, contaminadas com nitrato, têm causado problemas, tanto para animais como para o homem.

De forma análoga à região litorânea (tabela 3), os dados de pH da região serrana apresentam-se como uma distribuição simétrica ao redor da média. Aplicando-se o cálculo de percentil, observou-se que $91 \%$ dos dados se apresentaram em conformidade, enquanto que os resultados inadequados corresponderam aos $9 \%$ menores, abaixo do limite inferior definido pela legislação. Verificando-se o parâmetro dureza total, a região serrana apresentou um índice de conformidade de $67 \%$ com a faixa estabelecida. Quanto ao parâmetro cloretos, obteve-se aproximadamente metade das amostras coletadas abaixo do VMP da Portaria. Assim como a região litorânea, os dados para ambos os parâmetros também apresentaram alto grau de dispersão. Mais uma vez, o parâmetro nitratos apresentou alto grau de conformidade, aproximadamente $84 \%$. Analisando a última região, observou-se que o sertão apresentou o maior enquadramento de conformidade do parâmetro $\mathrm{pH}$, com $99,8 \%$ dentro do intervalo requerido pela legislação (Tabela 4). De forma semelhante às demais regiões, os dados apresentaram alto grau de dispersão em torno da média com índice de conformidade para dureza, cloretos e nitratos de $53 \%, 27 \%$ e $84 \%$, respectivamente.

Tabela 3 - Resultados obtidos para as amostras coletadas na região de serra

\begin{tabular}{c|c|c|c|c}
\hline \multirow{2}{*}{ Serra } & \multicolumn{4}{c}{ Resultados } \\
\cline { 2 - 5 } & $\mathrm{pH}$ à $25^{\circ} \mathrm{C}$ & $\begin{array}{c}\text { Dureza total } \\
\left(\mathrm{mgCaCO}_{3} \mathrm{~L}^{-1}\right)\end{array}$ & $\begin{array}{c}\text { Cloretos } \\
\left(\mathrm{mgCl}^{-1}\right)\end{array}$ & $\begin{array}{c}\text { Nitratos } \\
\left(\mathrm{mgNNO}_{3}-\mathrm{L}^{-1}\right)\end{array}$ \\
\hline Mínimo & 5,40 & 1,1 & 5,0 & 0,050 \\
Percentil 25\% & 6,70 & 130,8 & 96,4 & 0,063 \\
Mediana & 6,97 & 323,8 & 225,4 & 0,411 \\
Média & 6,94 & 406,6 & 341,9 & 3,372 \\
Percentil 75\% & 7,35 & 537,5 & 402,5 & 2,950 \\
Desvio Padrão Sx & 0,60 & 413,2 & 398,5 & 5,705 \\
Máximo & 8,06 & $2.168,1$ & $2.183,3$ & 20,782 \\
Portaria 2914/11 MS & $6,0-9,5$ & 500,0 & 250,0 & 10,0 \\
\hline
\end{tabular}

Fonte: Elaborada pelo autor (2016)

Tabela 4 - Resultados obtidos para as amostras coletadas na região de sertão

\begin{tabular}{c|c|c|c|c}
\hline \multirow{2}{*}{ Sertão } & \multicolumn{4}{c}{ Resultados } \\
\cline { 2 - 5 } & pH à 25 ${ }^{\circ} \mathrm{C}$ & $\begin{array}{c}\text { Dureza total } \\
\left(\mathrm{mgCaCO}_{3} \mathrm{~L}^{-1}\right)\end{array}$ & $\begin{array}{c}\text { Cloretos } \\
\left(\mathrm{mg} \mathrm{Cl-L}^{-1}\right)\end{array}$ & $\begin{array}{c}\text { Nitratos } \\
\left(\mathrm{mgNNO}_{3}-\mathrm{L}^{-1}\right)\end{array}$ \\
\hline Mínimo & 5,82 & 46,10 & 22,50 & 0,050 \\
Percentil 25\% & 7,00 & 270,70 & 230,30 & 0,050 \\
Mediana & 7,22 & 486,20 & 500,80 & 0,079 \\
Média & 7,22 & 721,88 & 768,61 & 5,351 \\
Percentil 75\% & 7,40 & 872,20 & 951,40 & 2,800 \\
Desvio Padrão Sx & 0,37 & 757,51 & 908,26 & 12,998 \\
Máximo & 8,19 & $4.350,90$ & $5.157,70$ & 65,100 \\
Portaria 2914/11 MS & $6,0-9,5$ & 500,0 & 250,0 & 10,0 \\
\hline
\end{tabular}

Fonte: Elaborada pelo autor (2016) 
É importante observar que dentre as duas regiões que tinham como domínio hidrogeológico predominante o embasamento cristalino, a região de serra foi a que apresentou melhores resultados em comparação com a região de sertão (Tabela 4). Como visto, as regiões serranas tendem a apresentar altos índices de pluviosidade, consequentemente, o grau de lixiviação ocasionado pelas chuvas tende a ser alto, o que colabora para a redução das concentrações de sais. Foi visto, também, nos municípios de maiores altitudes (regiões de serra) a temperatura é mais baixa que nas outras regiões, o que implica em um índice de evaporação baixo, ou seja, mais água se acumula e o teor de sais diminui. De forma análoga, no clima semiárido dos sertões, o índice de evaporação é muito elevado provocando um aumento gradual na concentração de sais das águas subterrâneas dos poços dessas regiões. Outro fator que contribui de forma semeIhante diz respeito à pluviosidade, que para a região do semiárido sertanejo é muito baixa o que não favorece o processo de lixiviação dos sais pela chuva, implicando, dessa forma, maiores concentrações de dureza e cloretos. Segundo a CPRM (1998), que fez um estudo analítico da viabilidade dos poços do interior do Ceará com foco nas formações sedimentares e cristalinas, os municípios com predominância de relevo cristalino geralmente são caracterizados por baixas vazões e péssima qualidade de água, sendo essa característica mais acentuada no sertão. Segundo Silva, Araújo e Souza (2007), no cristalino, o grau de conformidade com padrões da Portaria atinge a $47 \%$ e para uso agronômico, as águas subterrâneas do cristalino são mais restritivas, porém, especial atenção deve ser dada à toxicidade do íon cloreto.

\section{CONCLUSÃO}

Os resultados obtidos são bastante conclusivos para 0 cumprimento do objetivo geral deste trabalho, o qual se propôs a avaliar a qualidade de águas subterrâneas localizadas nas regiões de litoral, serra e sertão do Estado do Ceará destinadas ao consumo humano. A abrangência dos pontos de coleta, envolvendo diferentes regiões do Estado, demonstrou o quanto aspectos específicos relacionados com a geologia, o solo, a temperatura, a pluviometria e outros elementos naturais influenciam na potabilidade da água. Inicialmente, quanto às características peculiares dos parâmetros analisados, pode-se concluir que:

a) em todas as três regiões analisadas, as águas subterrâneas apresentaram elevadas concentrações de cloretos, sendo este o parâmetro que mais comprometeu a conformidade;

b) a concentração de cloretos mostrou-se ainda mais elevada na região dos sertões;

c) o parâmetro nitratos, o qual permite identificar agentes patogênicos causadores de doenças, e o parâmetro $\mathrm{pH}$ destacaram-se favoravelmente à potabilidade da água, com índices satisfatórios nas três regiões;

d) o parâmetro dureza, que identifica substâncias químicas que podem causar problemas de saúde, teve o pior índice no sertão e, de modo inverso, com relativa satisfatoriedade na região litorânea;

e) todas as três regiões apresentaram comportamento simétrico, característicos de uma Distribuição Normal, nos dados relativos ao parâmetro $\mathrm{pH}$; f) todas as regiões apresentaram elevada dispersão em torno da média dos dados para os parâmetros dureza total, cloretos e nitratos.

No que diz respeito a cada região, a conclusão quanto à qualidade da água para consumo humano deve considerar o cumprimento conjunto de todos os parâmetros estabelecidos pela legislação vigente do Ministério da Saúde. Comparando-se esses resultados com os padrões permitidos pela Portaria $n^{\circ}$ 2914/11 MS, extraem-se as seguintes constatações:

a) apesar das amostras de água subterrâneas de poços das cidades do sertão apresentarem um alto índice de conformidade de $\mathrm{pH}$ de $99,8 \%$, foram as mais inadequadas para consumo humano, em face dos menores índices de conformidade para os parâmetros dureza total e cloretos com $55 \%$ e $27 \%$, respectivamente;

b) os resultados obtidos nas amostras coletadas nas cidades serranas apresentaram índices melhores que nos municípios característicos do sertão, entretanto, os resultados ainda se mostraram relativamente insatisfatórios devido a um baixo índice de conformidade para cloretos de 55\%;

c) o melhor resultado conjunto das quatro análises químicas foi obtido para os municípios da região litorânea com índices de conformidade para os parâmetros $\mathrm{pH}$, dureza total, cloretos e nitratos de 75\%, 74\% 64\% e $90 \%$, respectivamente.

\section{REFERÊNCIAS}

ANA. AGÊNCIA NACIONAL DE ÁGUAS. Disponível: http://www.ana.gov.br. Acesso em: 10 maio. 2016.

APHA. AMERICAN PUBLIC HEALTH ASSOCIATION. AWWA. AMERICAN WATER WORKS ASSOCIATION. WEF. WATER ENVIRONMENT FEDERATION. Standard methods for the examination of water and wastewater. 22. ed. Washington, D.C. 2012.

ABAS. ASSOCIAÇÃO BRASILEIRA DE ÁGUAS SUBTERRÂNEAS. Disponível em: http://www.abas.org/educacao.php. Acesso em: 2 abril. 2016.

ANDRADE, E. M.; MEIRELES, A. C. M.; PALÁCIO, H. A. Q. O semiárido cearense e suas águas. In: ANDRADE, E. M.; PEREIRA, O. J.; DANTAS, F. E. R. (Org.). Semiárido e o manejo dos recursos naturais: uma proposta de uso adequado do capital natural. Fortaleza, CE: Imprensa Universitária da UFC, 2010. p. 56-80.

BAIRD, C. Química ambiental. 2. ed. Porto Alegre: Bookman, 2002. 622 p.

BECKER, H. Controle analítico de águas. Versão 4. Universidade Federal do Ceará. Fortaleza. 2010. 84 p.

BRAGA, B.; HESPANHOL, I.; CONEJO, J. G. L.; MIERWZA, J. C.; BARROS, M. T. L.; . Águas doces no Brasil: capital ecológico, uso e conservação. 3. ed. rev. ampl. São Paulo, SP: Escrituras, 2005. 748 p.

BRASIL. Ministério da Saúde. Portaria $n^{\circ} 2914$, de 12 de dezembro 2011. Dispõe sobre os procedimentos de controle e vigilância da qualidade da água para consumo humano e seu padrão de potabilidade. Brasília, 2011. 52 p. Disponível em: <http://177.153.6.85/portaria2914/theme/documentos/002.pdf>. Acesso em: 20 mar. 2015.

CAPUCCI, E.; MARTINS, A. M.; MANSUR, K. L.; MONSORES, A. L. M. Poços tubulares e outras captações de águas subterrâneas: orientação aos usuários. Rio de Janeiro, 2001.

COMPANHIA DE GESTÃO DE RECURSOS HÍDRICOS DO CEARÁ - COGERH. Plano de Gerenciamento das Águas das Bacias Metropolitanas. Fortaleza, 2000. 
COSTA, C. L.; LIMA, R. F.; PAIXÃO, G. C.; PANTOJA, L, D. M. Avaliação da qualidade das águas subterrâneas em poços do Estado do Ceará, Brasil. Semana: Ciências Biológicas e da Saúde, Londrina, v.33, n. 2, p. 171-180, jul/dez. 2012.

CPRM. Atlas digital dos recursos hídricos subterrâneos do Estado do Ceará. Fortaleza: CPRM/Serviço Geológico do Brasil, 1988. Disponível em: $<$ http://www.cprm.gov.br/publique/cgi/cgi-

lua.exe/sys/start.htm?sid=36\&infoid=588>. Acesso em: 2 mai. 2015.

DA SILVA. F. J. A.; ARAÚJO. A. L.; SOUZA, R. O. Águas subterrâneas no Ceará - poços instalados e salinidade. Rev. Tecnol. Fortaleza, v. 28, n. 2, 2007, p. 136-159.

FEITOSA FAC, MANOEL FILHO J, FEITOSA EC AND DEMETRIO JGA. 2008. Hidrogeologia: conceitos e aplicações. 3. ed., Rio de Janeiro: CPRM/LABHID, 812p.

FUNDACÃO CEARENSE DE METEOROLOGIA E RECURSOS HÍDRICOS FUNCEME. Disponivel em: <http://www.funceme.br/>. Acesso em 20 de mar 2015.

GREGHI, S. Q. Avaliação da eficiência de métodos rápidos usados para detecção de coliformes totais e coliformes fecais em amostras de água em comparação com técnicas de fermentação em tubos múltiplos. Universidade Estadual Paulista, Araraquara, 2005.
IRITANI, M. A.; EZAKI, S. As águas subterrâneas do Estado de São Paulo. São Paulo: Instituto Geológico, 2009. 104 p. Disponível em: <http://www.igeologico.sp.gov.br/downloads/livros/cart_AG_SB.pdf>. Acesso em: 20 abr. 2015.

LAPPONI, J. C. Estatística usando excel. 2. Ed. São Paulo: Lapponi Treinamento e Editora, 2000. 450p.

MINISTÉRIO DO MEIO AMBIENTE - MMA. Águas subterrâneas: um recurso a ser conhecido e protegido. Brasília, DF: Ministério do Meio Ambiente. Secretaria de Recursos Hídricos e Ambiente Urbano, 2007. 38 p. Disponível em:<http://www.mma.gov.br/estruturas/167/_publicacao/167_publicacao28012009044356.pdf >. Acesso em: 19 mar. 2015.

RODIER, J. Análisis de las aguas: aguas naturales, aguas residuales, agua do mar. Barcelona: Omega, 1990.

SPERLING, M. V. Introdução à qualidade das águas e ao tratamento de esgotos. 3. ed. Belo Horizonte, MG: UFMG. Departamento de Engenharia Sanitária e Ambiental, 2005. 452 p.

VALENTE, M. D. S. Manual prático de análise de água. 2. ed. Brasília: FUNASA, 2006.

ZIMBRES, E. Disponível em :<http://www.meioambiente.pro.br/agua/guia/aguasubterranea.htm>. Acesso em: 20 abri. 2015. 